\title{
Case teaching of maximum power transfer theorem in PV power system
}

\author{
Jiyong $\mathrm{Li}^{\mathrm{a}}$, Dongmei Wei ${ }^{\mathrm{b}}$ and Yan Huang ${ }^{\mathrm{c}}$ \\ Guangxi university, Nanning China \\ aji_yong_li@163.com, be349073356@qq.com, chyang923@qq.com
}

Keywords: Case teaching, maximum power transfer, PV power system

\begin{abstract}
The maximum power transfer theorem is discussed from the viewpoint of the case teaching method in this paper. Based on the output characteristic of PV cell, the principle of maximum power transfer in PV cell is analysed in detail. And simulation was carried out to verify maximum power transfer. This case teaching develops the ability to deal with practical problems which is the purpose of case teaching.
\end{abstract}

\section{Introduction}

In many practical situations, a circuit is designed to provide power to a load. There are applications in areas such as communications where it is desirable to maximize the power delivered to a load. In PV power system, the output voltage and power of PV cell varies with the level of solar radiation and ambient temperature corresponding to a specific weather condition, so PV power is a kind of unstable power. The output power is as much as possible which can raise efficiency of PV power systems under different conditions of solar radiation and temperature. The maximum power transfer theorem in circuit has a good application in PV power generation.

\section{The maximum power transfer theorem}

In the conventional linear system of electrical equipment, Thevenin equivalent is often used to analysis circuit $^{[1]}$. The Thevenin equivalent is useful in finding the maximum power a linear circuit can deliver to a load. We assume that we can adjust the load resistance $R_{\mathrm{L}}$. If the entire circuit is replaced by its Thevenin equivalent except for the load, as shown in Fig. $1^{[2]}$, the power delivered to the load is

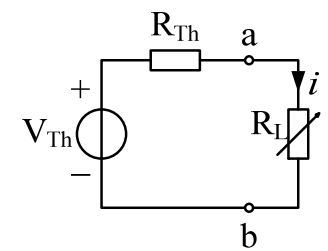

Fig.1. The circuit used for maximum power transfer

$$
p=i^{2} R_{\mathrm{L}}=\left(\frac{V_{\mathrm{Th}}}{R_{\mathrm{Th}}+R_{\mathrm{L}}}\right)^{2} R_{\mathrm{L}}
$$

For a given circuit, $V_{\mathrm{Th}}$ and $R_{\mathrm{Th}}$ are fixed. By varying the load resistance $R_{\mathrm{L}}$, the power delivered to the load varies as sketched in Fig.2. 


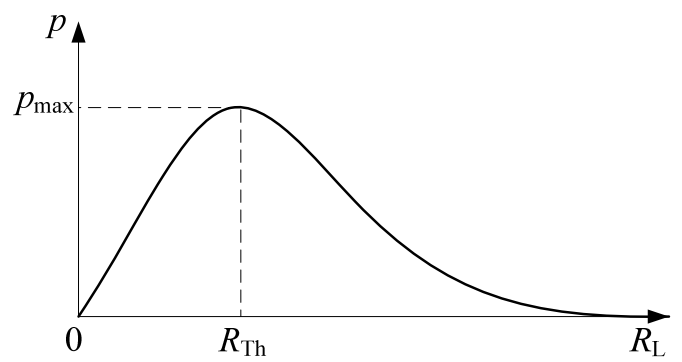

Fig.2. The power delivered to the load

To obtain the maximum power point, we differentiate $p$ in Eq. 1 with respect to $R_{\mathrm{L}}$ and set the result equal to zero. We obtain

$$
\begin{aligned}
\frac{d p}{d R_{\mathrm{L}}} & =V_{\mathrm{Th}}^{2}\left[\frac{\left(R_{\mathrm{Th}}+R_{\mathrm{L}}\right)^{2}-2 R_{\mathrm{L}}\left(R_{\mathrm{Th}}+R_{\mathrm{L}}\right)}{\left(R_{\mathrm{Th}}+R_{\mathrm{L}}\right)^{4}}\right] \\
& =V_{\mathrm{Th}}^{2}\left[\frac{\left(R_{\mathrm{Th}}+R_{\mathrm{L}}-2 R_{\mathrm{L}}\right)}{\left(R_{\mathrm{Th}}+R_{\mathrm{L}}\right)^{3}}\right]=0
\end{aligned}
$$

So we can yield that

$$
R_{\mathrm{Th}}=R_{\mathrm{L}}
$$

It can be seen that the maximum power transfer takes place when the load resistance $R_{\mathrm{L}}$ equals the Thevenin resistance $R_{\mathrm{Th}}$. The maximum power transferred is obtained by Equation(4).

$$
p_{\max }=\frac{V_{\mathrm{Th}}^{2}}{4 R_{\mathrm{Th}}}
$$

This is known as the maximum power transfer theorem

\section{The output characteristic of PV cell}

Photovoltaic cells consist of a silicon P-N junction that when exposed to light releases electrons around a closed electrical circuit. From this premise the circuit equivalent of a PV cell can be modeled through the circuit shown in Fig. $3^{[3,4]}$. Electrons from the cell are excited to higher energy levels when a collision with a photon occurs. These electrons are free to move across the junction and create a current. This is modeled by the light generated current source $\left(I_{p h}\right)$. The intrinsic P-N junction characteristic is introduced as a diode in the circuit equivalent ${ }^{[5]}$.

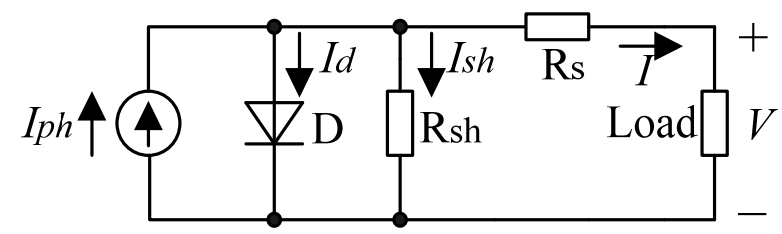

Fig.3. Photovoltaic cell equivalent circuit

According to the equivalent circuit and features, it is known that the characteristic of PV will be changed when $S$ and $T$ change. Changes in these variables $S$ and $T$ cause the current-voltage $(I-V)$ curves of photovoltaic array to change as well, as illustrated in Fig. 4 and Fig. 5, where $S$ symbolizes the solar illumination, and $T$ is temperature. 


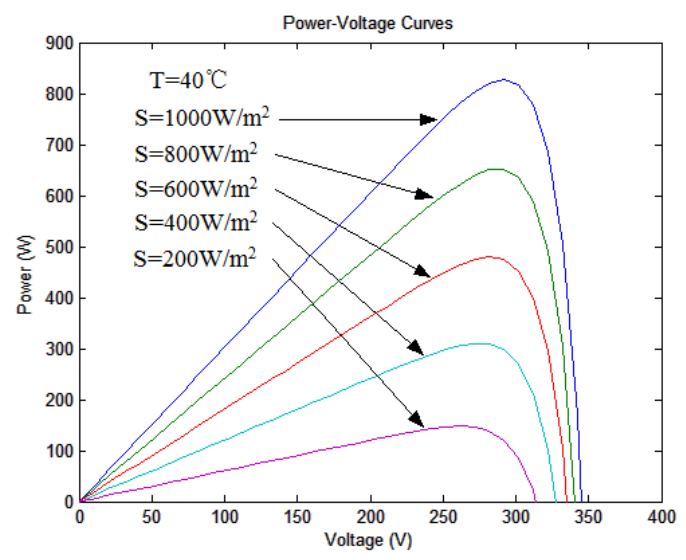

Fig.4. Power versus voltage curves influence by the solar illumination

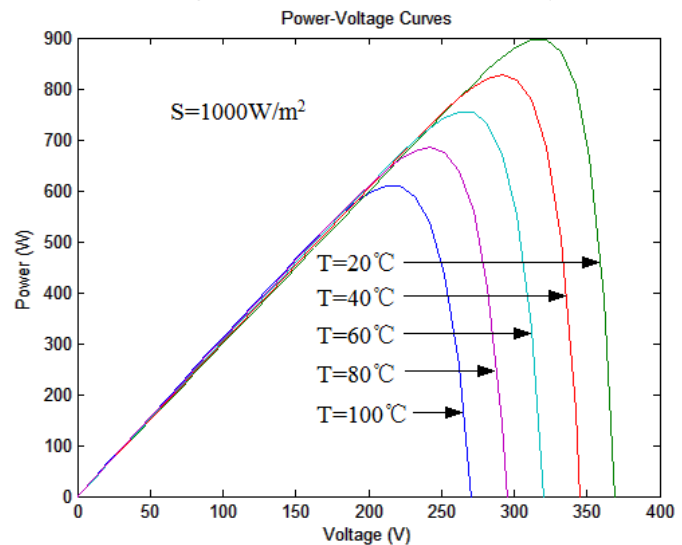

Fig.5. Power versus voltage curves influence by temperature

From Fig. 4 and Fig. 5, it can be seen that the output power of a PV module is influenced by the solar illumination and ambient temperature.

\section{Application of the maximum power transfer theorem in PV power system}

In PV power system, internal resistance of PV cell is not only affected by the intensity of sunlight, but also influenced by temperature and load, which is always change. We can take advantage of the maximum power transfer theorem in circuit. An impedance transformer is inserted between the solar photovoltaic power and load which is used to match the load and the change of PV cell internal resistance, so as to make the output power of PV cell to the maximum. Maximum power output of PV cell's structure is shown in Fig.6. Load and changing resistance in PV cell power can been always matched by control algorithm, so that the output power of PV cell power has been in a maximum.

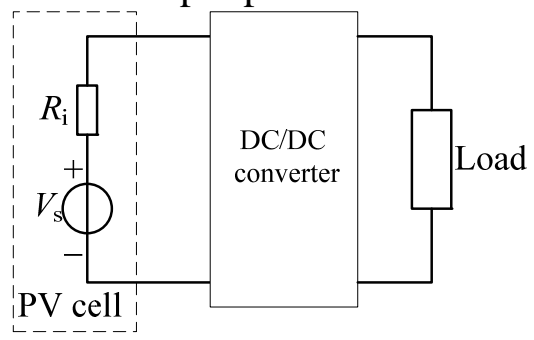

Fig.6 Maximum output power circuit structure

In order to verify the application of maximum power transfer theorem in PV power system, the corresponding simulation has been performed in Matlab/Simulink software. The result of simulation can be seen in Fig.7. 


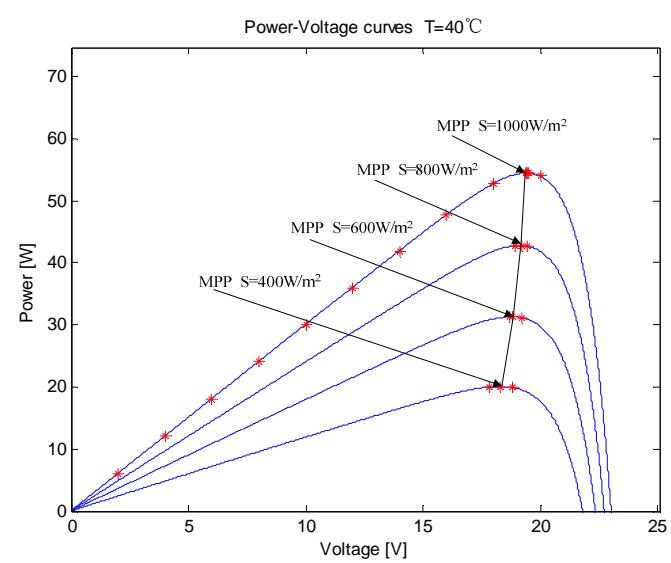

Fig.7. Power transfering process in PV power system

In Fig.7, it shows that the output power of PV cell has been always in a maximum, so the maximum power transmission is implemented in PV power system.

\section{Conclusion}

Maximum power transfer theorem is an important theorem in circuit theory, also must consider the actual problems in the new energy power generation such as PV power. Therefore the maximum power transmission theory used in the photovoltaic power generation in teaching will help students further understand the theorem.

\section{Acknowledgements}

This work was financially supported by the Academic Research Project of Guangxi Education Department (2013YB015), the 2013 key projects of Guangxi higher education teaching reform project (2013JGZ101), the laboratory construction and experimental teaching reform projects of Guangxi university(20120202).

\section{References}

[1] Qiu Guanyuan. electric circuits (5th). Beijing: Higher Education Press, 2006.

[2] Alexander, Charles K., Sadiku, Matthew N.O. Fundamentals of electric circuits. McGraw-Hill, 2013.

[3] Cuauhtemoc Rodriguez, and Gehan A. J Amaratunga, "Analytic Solution to the Photovoltaic Maximum Power Point Problem," IEEE Transactions on Circuit and Systems, Vol. 54, No. 9, pp. 2054-2060, September, 2007.

[4] Ashish Pandey, Nivedita Dasgupta, and Ashok Kumar Mukkerjee, "High-Performance Algorithms for Drift Avoidance and Fast Tracking in Solar MPPT System," IEEE Transactions on Energy Conversion, Vol. 23, No. 2, pp. 681-689, June, 2008.

[5] S. Jain, and V. Agarwal, "Comparision of the performance of maximum power point tracking schemes applied to single-stage grid-connected photovoltaic systems,” IET Electr. Power Appl., Vol. 1, No. 5, pp. 753-762, September 2007. 